\title{
Surface yttria content and hydrothermal ageing behaviour of two step sintered 3Y-TZP ceramics
}

\author{
U Sutharsini ${ }^{1 *}$, M Thanihaichelvan ${ }^{1}, \mathrm{~S} \mathrm{Ramesh}^{2}$ and $\mathrm{CK} \mathbf{N g}^{3}$ \\ ${ }^{I}$ Department of Physics, Faculty of Science, University of Jaffina, Jaffina. \\ ${ }^{2}$ Centre of Advanced Manufacturing and Material Processing (AMMP), Department of Mechanical Engineering, Faculty of Engineering, \\ University of Malaya, 50603, Kuala Lumpur, Malaysia. \\ ${ }^{3}$ Centre for Advanced Materials, Department of Materials Engineering, Faculty of Engineering and Technology, Tunku Abdul Rahman University \\ College, 53300, Kuala Lumpur, Malaysia.
}

\begin{abstract}
In this work the effect of surface yttria concentration on hydrothermal ageing of two-step sintered (TSS) 3 mol. \% yttria stabilised tetragonal zirconia polycrystalline (3Y-TZP) ceramics was investigated. Green compacts were prepared by bench pressing and sintered using a two-step sintering with first step sintering temperature of $1400^{\circ} \mathrm{C}$ for one minute and second step sintering temperature of $1200^{\circ} \mathrm{C}$ at different holding times of 2, 10 and 20 hours. Surface morphology and surface yttria content of the sintered samples were investigated by using Xray florescence spectroscopy (XRF) and field emission scanning electron microscopy (FESEM), respectively. It was found that the TSS effectively suppressed the grain growth. Increasing the holding time increased densification. Also, an increment in the surface yttria content with increasing holding time was observed. The ageing studies were conducted in an autoclave containing super-heated steam at $180^{\circ} \mathrm{C}$ and 10 bar pressure for 100 hours. Ageing resistance increased with increasing second step sintering time. The enhanced hydrothermal degradation of lower holding time samples can be attributed to the deficiency of surface yttria. Effect of ageing on surface yttria concentration and surface morphology were also investigated by using XRF and FESEM, respectively. The surface yttria concentration decreased with ageing which confirms leach out of surface yttria during hydrothermal ageing.
\end{abstract}

Keywords: 3Y-TZP, hydrothermal ageing, surface yttria content, two-step sintering, XRF.

\section{INTRODUCTION}

Zirconium composites are derived from natural minerals, mainly zircon $\left(\mathrm{ZrSiO}_{4}\right)$ and baddeleyite $\left(\mathrm{ZrO}_{2}\right)$. Zirconia was first found from Zircon from Sri Lankan beach sand (Kreidl, 1942). Zirconium oxide is stabilised in their tetragonal phase by 3 mol.\% yttrium oxide. 3 mol.\% yttria-stabilised tetragonal zirconia polycrystalline (3Y-TZP) ceramic is one of the most widely used ceramic materials in various applications. It is used as grinding media, cutting tools, spares for chemical pumps, roller guides, and tweezers (Jue et al., 1991; Liang et al., 2009). Yttria stabilised tetragonal zirconia polycrystals (Y-TZP) are increasingly used as biomaterial particularly in dental and bone restorations in recent years due to its superior mechanical properties, chemical and environmental inertness, biocompatibility and aesthetic nature (Piconi \& Maccauro, 1999; Chevalier, 2006; Flinn et al., 2012). The martensitic nature of tetragonal to monoclinic phase transformation is one of the extreme technological importance in zirconia ceramics (Subbarao et al., 1974). Transformation toughening in zirconia is a landmark innovation in obtaining high strength and toughness ceramic as first reported by Garvie et al. (1975). The retention of tetragonal phase is an essential prerequisite

*Corresponding author (ubsutharsini@univ.jfn.ac.lk; iD https://orcid.org/0000-0003-2695-7153)

This article is published under the Creative Commons CC-BY-ND License (http://creativecommons.org/licenses/by-nd/4.0/). This license permits use, distribution and reproduction, commercial and non-commercial, provided that the original work is properly cited and is not changed in anyway. 
for toughening, since in the presence of a propagating crack the tetragonal particles are induced to transform to the monoclinic phase with an accompanying volume expansion of 3-5\%. Consequently, an advancing crack is subjected to a compressive stress, its progress is either halted or retarded, and the material is toughened. This is quite similar to the toughening mechanism in some steels and as such zirconia has been labelled 'ceramic steel' (Garvie et al., 1975). However, the mechanical properties deteriorate rapidly in the presence of moisture at relatively low temperature $\left(65-500^{\circ} \mathrm{C}\right)$, a phenomenon known as low temperature degradation (LTD) or hydrothermal ageing (Lawson, 1995). During hydrothermal ageing, the metastable tetragonal zirconia surface grains transform to monoclinic phase accompanied with volume expansion. Volume expansion in the compact ceramic leads to microcracks (Kobayashi et al., 1981), grain pullout and finally surface roughening (Lawson, 1995; Bartolomé et al., 2004; HernándezMontoya et al., 2012), which eventually leads to property degradation and failure in the ceramic sample. Many studies have been carried out on the tetragonal to monoclinic phase transformation (ageing) in the recent past. It was reported that the ageing depends on grain size (Lawson, 1995; Yasuda et al., 1999; Chevalier et al., 2004), stabiliser concentration (Kobayashi et al., 1981; Thompson and Rawlings, 1992), dopant (Hernandez et al., 1991; Lawson, 1995; Nur Nadia et al., 2017; Zhang et al., 2017), and environmental condition (Lawson, 1995).

Grain size of the 3Y-TZP was controlled by tailoring the sintering condition (Mazaheri et al., 2008; Sutharsini et al., 2018, 2017, 2014b; Vignarajah et al., 2019). Grain size increased with increasing sintering temperature (Ramesh \& Gill, 2001; Ramesh et al., 2013, 2016, 2018; Sutharsini et al., 2014a; b, 2017, 2018; Ting et al., 2016; Ubenthiran et al., 2018; Dhuban et al., 2019; $\mathrm{Ng}$ et al., 2019; Vignarajah et al., 2019). However, high temperature sintering is important for densification which directly influences the mechanical properties. Two step sintering is a promising approach to achieve high densities with controlled grain growth (Mazaheri et al., 2008; Sutharsini et al., 2014b, 2017, 2018; Vignarajah et al., 2019). In the two-step sintering technique, the samples are sintered at higher temperature for a short time to achieve critical grain size and then it is sintered at lower temperature for a long time to reach maximum densification. As reported earlier, the TSS samples showed excellent hydrothermal ageing resistance and high densification (Sutharsini et al.,2017). It was also observed that ageing resistance increased with increasing holding time but without any significant changes in the grain size. In this work, different ageing behaviours of the two-step sintered 3 Y-TZP ceramic with different holding times were investigated but with the same grain size. The surface yttria content of the samples was investigated and the results were analysed.

\section{METHODOLOGY}

Green samples were prepared by using 3 mol.\% yttriastabilised tetragonal zirconia polycrystalline powder (Kyoristu, Japan) and the pressing method reported elsewhere (Ubenthiran et al., 2013; 2018; Sutharsini et al., 2014a;b, 2017). Two step sintering technique was used to sinter the samples. Green samples were initially heated to the first step sintering temperature of $1400{ }^{\circ} \mathrm{C}$ and held at that temperature for $1 \mathrm{~min}$, cooled down to $1200{ }^{\circ} \mathrm{C}$ and held at the same temperature for different holding times of $2 \mathrm{~h}, 10 \mathrm{~h}$ and $20 \mathrm{~h}$. Thereafter, the samples were allowed to cool down to room temperature. The heating and cooling rate was fixed at $10^{\circ} \mathrm{C} / \mathrm{min}$. Assintered samples were aged in a stainless-steel autoclave containing superheated water steam at the temperature $180^{\circ} \mathrm{C}$ and pressure 10 bar up to $100 \mathrm{~h}$.

Crystal structure of the samples was investigated by using X-ray diffraction (XRD) (PANalytical Empyrean, Netherlands). Phase transformation was estimated by using the method proposed by Toraya et al. (1984). Surface yttria content of the as-sintered and aged 3 Y-TZP ceramics was measured using a micro-XRF analyser. The XRF measurements were conducted at 20 $\mathrm{kV}$ and $700 \mu \mathrm{A}$ with a spot size of $30 \mu \mathrm{m}$ on as-sintered and aged samples by using Orbis micro-XRF analyzer. Hundred points were randomly selected on the surface to obtain average surface yttria concentration and distribution. Microstructural evaluation was conducted by using FESEM (Auriga Zeiss Ultra-60). The samples were polished and thermally etched before FESEM investigation for clear identification of grains. Average grain sizes of the samples were calculated by line intercept method (ASTM, 2013).

\section{RESULTS AND DISCUSSION}

\section{Results}

Microstructural properties of the as-sintered 3Y-TZP samples were studied using FESEM. Figure 1 shows the FESEM images of as-sintered samples. The micrographs revealed uniform grain size and distribution regardless of sintering holding time as shown in Figure 1 (a)-(c). Grain size of the samples as-sintered at holding times of 
2 hours, 10 hours and 20 hours were measured as $0.29 \pm$ $0.16 \mu \mathrm{m}, 0.29 \pm 0.021 \mu \mathrm{m} 0.28 \pm 0.024 \mu \mathrm{m}$, respectively.
There were no significant changes observed in the samples regardless of the holding time.
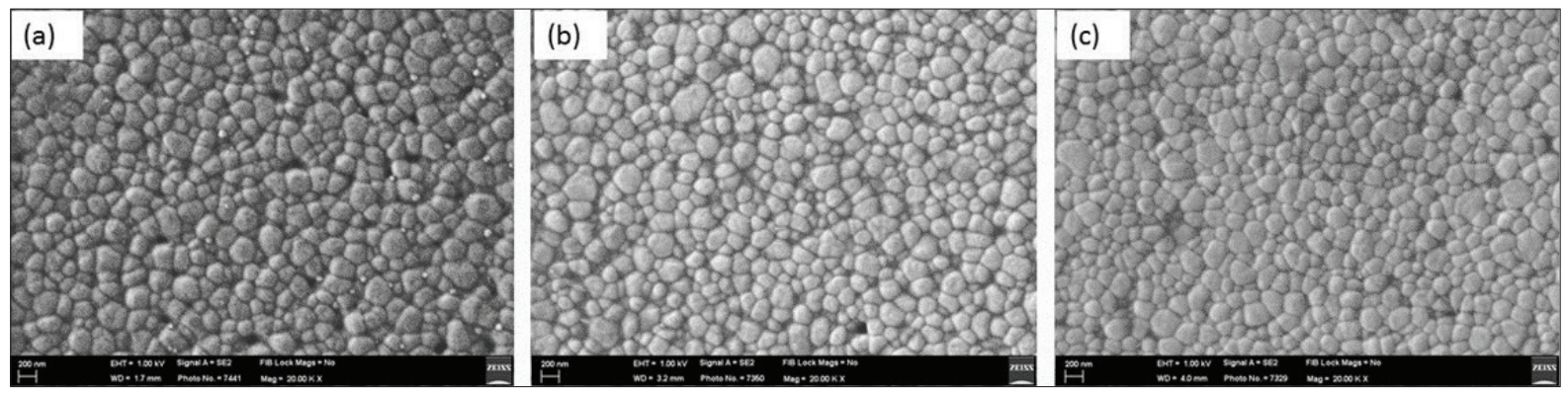

Figure 1: FESEM images of two-step sintered 3Y-TZP samples at a first step sintering temperature of $1400^{\circ} \mathrm{C}$ and a second step sintering temperature of $1200^{\circ} \mathrm{C}$ with (a) 2 hours; (b) 10 hours and (c) 20 hours holding times.

The surface yttria content of the as-sintered samples was also measured. The effect of holding time on surface concentration is shown in Figure 2. As the holding time increased, surface yttria concentration increased and a narrow distribution is observed for long holding times. The average surface yttria content of the samples sintered with holding times of 2 hours, 10 hours, and 20 hours were measured as $2.48 \pm 0.19,2.62 \pm 0.15$, and $2.74 \pm 0.09 \mathrm{~mol} \%$, respectively. Hence, it was evident that the surface yttria content increases with increasing holding time. Moreover, the yttria distribution curve got narrower with increased holding time.

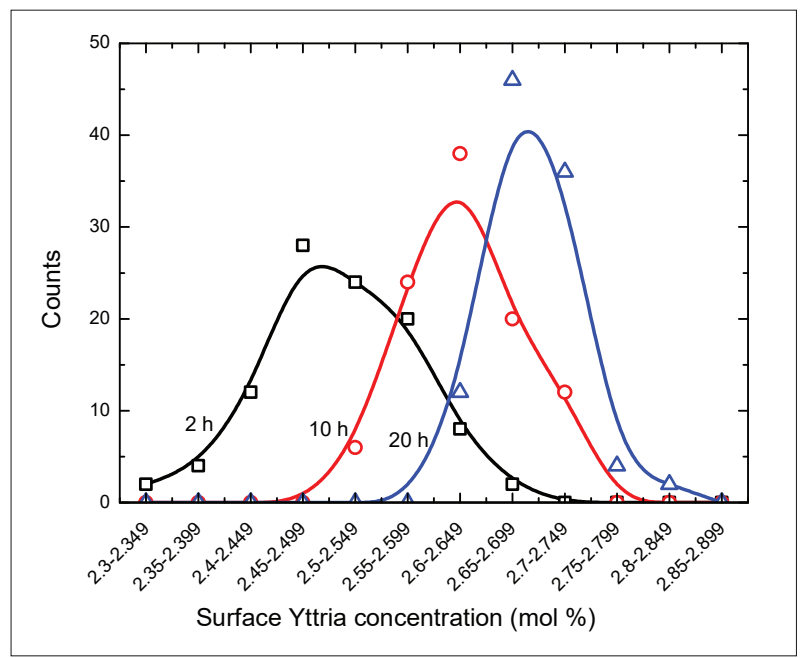

Figure 2: Distribution of surface yttria content of the samples sintered using TSS with holding times of 2, 10, and 20 hours.
Figure 3 (a) shows the monoclinic phase development of the TSS samples. The FESEM images of the aged samples with different holding times are shown in Figure 3 (b)-(d). The effect of tetragonal to monoclinic transformation on surface microstructure is clearly shown in Figure 3 (b)(d). The average grain size was not changed with ageing. The catastrophic consequence of ageing is clearly visible through FESEM images [Figure 3 (b) and Figure 3 (d)]. The sample sintered with 2 hours holding time [Figure 3 (a)] showed $42 \%$ of monoclinic content and the sample is disintegrated into debris as shown in Figure 3 (b). General observations of ageing such as microcrack, and surface roughening can be seen Figure 3 (c). This sample is with 10 hours holding time and exhibited only $3 \%$ of monoclinic phase transformation. Grain pullout is clearly visible in this microstructure of the aged samples with 2 hours and 10 hours holding time. Neither phase transformation nor surface defects were observed for the sample sintered for 20 hours and hence Figure 1 (c) and Figure 3 (d) are exhibiting similar microstructures.

\section{Discussion}

The experimental data clearly shows that the two-step sintering suppress the grain growth of 3 Y-TZP ceramics. There were no significant changes observed in the grain size even if the holding time was extended up to 20 hours. As a result, it is possible that the sintering profile $\left(1400{ }^{\circ} \mathrm{C}\right.$ as first step temperature for $1 \mathrm{~min}$ and $1200^{\circ} \mathrm{C}$ as second step temperature with different holding times of 2 hours, 10 hours and 20 hours) used in this work lies within the kinetic window of 3 Y-TZP (Sutharsini et al., 2018). However, an increment in relative density was observed in a previous study (Sutharsini et al., 2017). As 


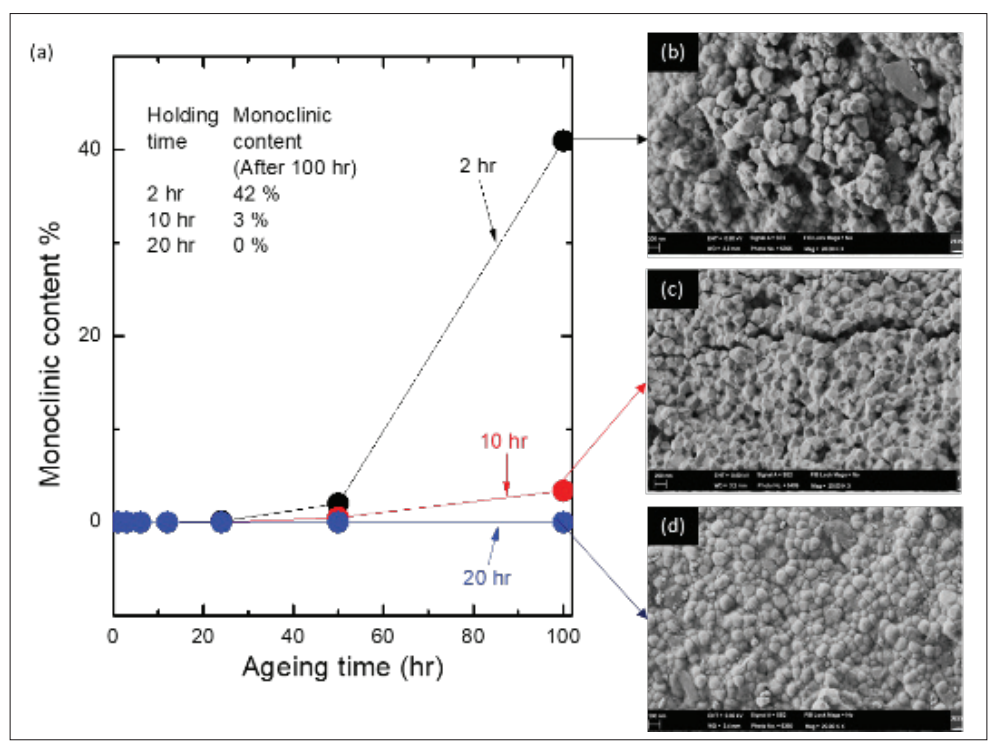

Figure 3: (a) Monoclinic phase development of the TSS samples sintered at different holding time and FESEM images of $100 \mathrm{~h}$ aged samples with (b) 2 hours; (c) 10 hours and (d) 20 hours holding times.

reported earlier, TSS freeze the grain growth at the end of first step sintering and densification was achieved during the second step sintering. The dominant mechanism for frozen grain growth is suppression of grain boundary migration before the second stage of sintering caused by immobilizing the triple-point junctions, due to rapid cooling after first step sintering and densification achieved by grain boundary diffusion (Sutharsini et al., 2018). Then it was found that TSS enhanced the hydrothermal ageing resistance which is consistent with previous work (Sutharsini et al., 2017, 2018; Vignarajah et al., 2019). The interesting observation here is that two step sintering revealed different ageing behaviours for different samples with the same grain size distribution. In addition, regardless of the same grain size, the tetragonal to monoclinic phase transformation decreased with increasing sintering holding time (Sutharsini et al., 2017, 2018; Vignarajah et al., 2019). To identify the mechanism behind the unique ageing behaviour, the surface yttria concentration of the samples was studied. A correlation between the surface yttria content and ageing behaviour of TSS samples with different holding times was found. Sample with the highest surface yttria content showed no phase transformation even after 100 hours of ageing. Also the monoclinic content after 100 hours of ageing increased with reducing surface yttria content. It suggests that uniform and high surface yttria distribution might enhanced hydrothermal ageing resistance of the sample sintered with holding time of 20 hours.
In order to study the effect of ageing on surface yttria concentration, surface yttria concentration of the assintered and 100 hour-aged sample were measured. Then, the 100 hour-aged sample was re-sintered and surface yttria content was measured. Re-sintering was done using single step sintering at $1400{ }^{\circ} \mathrm{C}$ for 2 hours. Figure 4 shows the average surface yttria concentration of the as-sintered, 100 hour-aged and re-sintered samples. It is clearly seen that the ageing reduces the surface yttria content. Decrease in yttria concentration with hydrothermal ageing is reported by some researchers (Thompson \& Rawlings, 1992; Kimel \& Adair, 2002; Ho \& Wei, 2004; Papanagiotou et al., 2006). The reduction in surface yttria content can be explained in two ways: 1) grain pull-out and 2) yttria leach-out during ageing. Firstly, ageing induced grain pull-out expose the interior grains potentially with low yttria content. Thompson and Rawlings (1992) proposed that tetragonal to monoclinic phase transformation is a consequence of the leaching of the yttrium from the zirconia particles thereby reducing their stability. Papanagiotou et al. (2006) and Sutharsini et al. (2017) also supported that loss of yttria, which could potentially reduce the tetragonal phase stability. However, Ho and Wei (2004) observed the different trends between yttrium dissolution and monoclinic phase transformation. Hence, they proposed that yttria dissolution is not the controlling factor leading to the monoclinic phase transformation. On the other hand, Lange et al. (1986) reported the formation of $\alpha-\mathrm{Y}(\mathrm{OH})_{3}$ 
crystallite on the aged sample. They also postulate that there could be a possible Yttrium diffusion during ageing. However, Yoshimura et al. (1989) disproved the yttria diffusion theory due to the very slow yttria diffusion at low temperatures.

Therefore, it is suspected that the reduction in surface yttria concentration confirmed yttria leach out from the surface grain during hydrothermal ageing. It is therefore proposed that the mechanism of hydrothermal ageing relies on dissolution of yttria from 3Y-TZP ceramics. Removal of surface yttria concentration reduces the tetragonal stability of 3Y-TZP ceramics. As a result, tetragonal zirconia transformed to monoclinic zirconia with hydrothermal ageing.

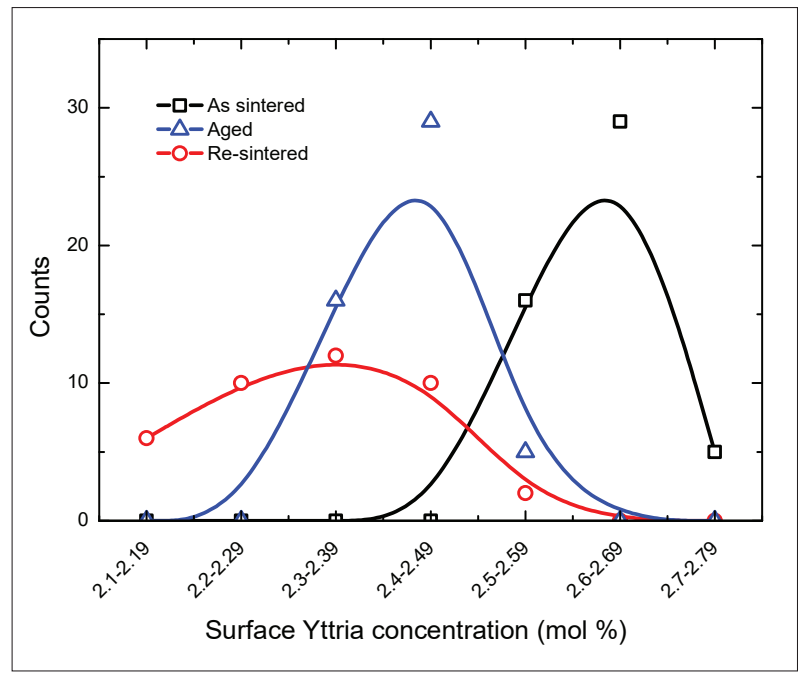

Figure 4: Distribution of surface yttria content of the as-sintered, 100 hour-aged and re-sintered 3Y-TZP samples.

\section{CONCLUSIONS}

It was shown that TSS can be used as a tool to achieve highly dense 3Y-TZP ceramic with controlled grain growth and excellent hydrothermal ageing resistance. Surface yttria content of the two-step sintered 3Y-TZP is not exactly $3 \%$ and it increases with increasing second step holding time. Hence, it was postulated that the surface yttria content is an important factor in determining the ageing resistance of two-step sintered 3 Y-TZP ceramic with the same grain size. Surface yttria concentration decreased after 100 hours of ageing, which is a direct evidence for yttria leach out during ageing. It can be concluded that keeping the surface yttria content nearly $3 \%$ in the as-sintered articles would enhance the ageing resistance of $3 \mathrm{Y}-\mathrm{TZP}$ ceramics.

\section{Conflict of interest}

Authors declare no conflict of interest.

\section{Acknowledgements}

The authors acknowledge the National Science Foundation (NSF) of Sri Lanka for the financial support (Research Grant: RG/2017/BS/04).

\section{REFERENCES}

ASTM (2013). E112-13: Standard test methods for determining average grain size. American Society for Testing and Materials Int., West Conshohocken, PA, USA.

DOI: https://doi.org/10.1520/E0112-13

Bartolomé J.F., Montera I., Díaz M., López-Esteban S., Moya J.S., Deville S., Gremillard L., Chevalier J. \& Fantozzi G. (2004). Accelerated aging in 3-mol\%-yttria-stabilised tetragonal zirconia ceramics sintered in reducing conditions. Journal of American Ceramic Society 87(12): 2282-2285. DOI: https://doi.org/10.1111/j.1151-2916.2004.tb07505.x

Chevalier J. (2006). What future for zirconia as a biomaterial? Biomaterials 27(4): 535-543.

DOI: https://doi.org/10.1016/j.biomaterials.2005.07.034

Chevalier J., Deville S., Münch E., Jullian R. \& Lair F. (2004). Critical effect of cubic phase on aging in $3 \mathrm{~mol} \%$ yttriastabilised zirconia ceramics for hip replacement prosthesis. Biomaterials 25(24): 5539-5545.

DOI: https://doi.org/10.1016/j.biomaterials.2004.01.002

Dhuban S.B., Ramesh S., Tan C.Y., Wong Y.H., Johnson Alengaram U., Teng W.D., Tarlochan F. \& Sutharsini U. (2019). Sintering behaviour and properties of manganesedoped alumina. Ceramics International 45(6): 7049-7054. DOI: https://doi.org/10.1016/j.ceramint.2018.12.207

Flinn B.D., Degroot D.A., Mancl L.A. \& Raigrodski A.J. (2012). Accelerated aging characteristics of three yttriastabilised tetragonal zirconia polycrystalline dental materials. Journal of Prosthetic Dentistry 108(4): 223-230. DOI: https://doi.org/10.1016/S0022-3913(12)60166-8

Garvie R.C., Hannink R.H. \& Pascoe R.T. (1975). Ceramic steel? Nature 258: 703-704.

DOI: https://doi.org/10.1038/258703a0

Hernandez M.T., Jurado J.R., Duran P. \& Fierro J.L.G. (1991). Sub eutectoid degradation of yttria-dtabilised tetragonal zirconia polycrystal and ceria-doped yttria-stabilised tetragonal zirconia polycrystal ceramics. Journal of American Ceramic Society 74(6): 1254-1258.

DOI: https://doi.org/10.1111/j.1151-2916.1991.tb04094.x

Ho F.Y. \& Wei W.C.J. (2004). Dissolution of yttrium ions and phase transformation of $3 \mathrm{Y}-\mathrm{TZP}$ powder in aqueous 
solution. Journal of American Ceramic Society 82(6): 1614-1616.

DOI: https://doi.org/10.1111/j.1151-2916.1999.tb01971.x

Jue J.F., Chen J. \& Virkar A. V. (1991). Low-temperature aging of $\mathrm{t}^{\prime}$-zirconia: The role of microstructure on phase stability. Journal of American Ceramic Society 74(8): 1811-1820. DOI: https://doi.org/10.1111/j.1151-2916.1991.tb07793.x

Kimel R.A. \& Adair J.H. (2002) Aqueous degradation and chemical passivation of yttria-tetragonally-stabilised zirconia at $25^{\circ} \mathrm{C}$. Journal of American Ceramic Society 85(6): 1403-1408.

DOI: https://doi.org/10.1111/j.1151-2916.2002.tb00288.x

Kobayashi K., Kuwajima H. \& Masaki T. (1981). Phase change and mechanical properties of $\mathrm{ZrO}_{2}-\mathrm{Y}_{2} \mathrm{O}_{3}$ solid electrolyte after ageing. Solid State Ionics 3-4: 489-493.

DOI: https://doi.org/10.1016/0167-2738(81)90138-7

Kreidl N.J. (1942). Zirconium oxide and thorium oxide in ceramics. Journal of the American Ceramic Society 25(5): 129-141.

DOI: https://doi.org/10.1111/j.1151-2916.1942.tb14362.x

Lange F.F., Dunlop G.L. \& Davis B.I. (1986). Degradation during aging of transformation-toughened $\mathrm{ZrO}_{2}-\mathrm{Y}_{2} \mathrm{O}_{3}$ materials at $250^{\circ} \mathrm{C}$. Journal of American Ceramic Society 69: 237-240.

DOI: https://doi.org/10.1111/j.1151-2916.1986.tb07415.x

Lawson S. (1995). Environmental degradation of zirconia ceramics. Journal of European Ceramic Society 15(6): 485-502.

DOI: https://doi.org/10.1016/0955-2219(95)00035-S

Liang B., Ding C., Liao H. \& Coddet C. (2009). Study on structural evolution of nanostructured $3 \mathrm{~mol} \%$ yttria stabilised zirconia coatings during low temperature ageing. Journal of European Ceramic Society 29(11): 2267-2273. DOI: https://doi.org/10.1016/j.jeurceramsoc.2009.01.002

Mazaheri M., Simchi A. \& Golestani-Fard F. (2008). Densification and grain growth of nanocrystalline 3Y-TZP during two-step sintering. Journal of European Ceramic Society 28(15): 2933-2939.

DOI: https://doi.org/10.1016/j.jeurceramsoc.2008.04.030

Ng C.K., Ramesh S., Tan C.Y., Muchtar A., Somalu M.R., Samuel Lew W.S., Ting C.H., Chuah Y.D. \& Sutharsini U. (2019). Thermal stability behaviour of Scandia stabilised zirconia, in: IOP Conference Series: Earth and Environmental Science 268: 012078.

DOI: https://doi.org/10.1088/1755-1315/268/1/012078

Nur Nadia A.H., Ramesh S., Tan C.Y., Wong Y.H., Zainal Abidin N.I., Teng W.D., Sutharsini U. \& Sarhan A.A.D. (2017). The effects of sintering additives on the mechanical properties and microstructure evolution of $3 \mathrm{~mol} \% \mathrm{Y}-\mathrm{TZP}$. Journal of Ceramic Processing Research 18(7): 483-487.

Papanagiotou H.P., Morgano S.M., Giordano R.A. \& Pober R. (2006). In vitro evaluation of low-temperature aging effects and finishing procedures on the flexural strength and structural stability of Y-TZP dental ceramics. Journal of Prosthetic Dentistry 96(3): 154-164.

DOI: https://doi.org/10.1016/j.prosdent.2006.08.004

Piconi C. \& Maccauro G. (1999). Zirconia as a ceramic biomaterial. Biomaterials 20(1): 1-25.
DOI: https://doi.org/10.1016/S0142-9612(98)00010-6

Ramesh S. \& Gill C. (2001). Environmental degradation of $\mathrm{CuO}$-doped Y-TZP ceramics. Ceramics International 27(6): 705-711.

DOI: https://doi.org/10.1016/S0272-8842(01)00024-4

Ramesh S., Kelvin Chew W.J., Tan C.Y., Purbolaksono J., Noor A.M., Hassan M.A., Sutharsini U., Satgunam M. \& Teng W.D. (2013). Influence of manganese on the sintering properties of tetragonal zirconia. Ceramic Silikaty 57(1): 28-32.

Ramesh S., Khan M.M., Alexander Chee H.C., Wong Y.H., Ganesan P., Kutty M.G., Sutharsini U., Chew W.J.K. \& Niakan A. (2016). Sintering behaviour and properties of graphene oxide-doped Y-TZP ceramics. Ceramics International 42(15): 17620-17625.

DOI: https://doi.org/10.1016/j.ceramint.2016.08.077

Ramesh S., Sara Lee K.Y., Tan C.Y., Wong Y.H., Johnson Alengaram U., Tarlochan F., Ramesh S., Teng W.D., Sutharsini U. \& Sarhan A.A.D. (2018). Effect of microwave sintering on the properties of copper oxide doped Y-TZP ceramics. Ceramics International 44(16): 19639-19645. DOI: https://doi.org/10.1016/j.ceramint.2018.07.215

Subbarao E.C., Maiti H.S. \& Srivastava K.K. (1974). Martensitic transformation in zirconia. Physica Status Solidi 21(1): 9-40.

DOI: https://doi.org/10.1002/pssa.2210210102

Sutharsini U., Ramesh S., Purbolaksono J., Tan C.Y., Teng W.D. \& Amiriyan M. (2014a). Low-temperature degradation and defect relationship in yttria-tetragonal zirconia polycrystal ceramic. Materials Research Innovations 18: S6-131-S6134.

DOI: https://doi.org/10.1179/1432891714Z.000000000943

Sutharsini U., Ramesh S., Wong Y.H., Misran H., Yusuf F., Tan C.Y., Purbolaksono J., Teng W.D. (2014b). Effect of sintering holding time on low-temperature degradation of yttria stabilised zirconia ceramics. Materials Research Innovations 18: S6-408-S6-411.

DOI: https://doi.org/10.1179/1432891714Z.000000000988

Sutharsini U., Thanihaichelvan M. \& Singh R. (2018). Twostep sintering of ceramics. In: Sintering of Functional Materials (ed. I. Shishkovsky), pp. 3-21, IntechOpen Limited., London, United Kingdom.

DOI: https://doi.org/10.5772/68083

Sutharsini U., Thanihaichelvan M., Ting C.H., Ramesh S., Tan C.Y., Chandran H., Sarhan A.A.D., Ramesh S. \& Urriés I. (2017). Effect of two-step sintering on the hydrothermal ageing resistance of tetragonal zirconia polycrystals. Ceramics International 43(10): 7594-7599.

DOI: https://doi.org/10.1016/j.ceramint.2017.03.052

Thompson I. \& Rawlings R.D. (1992). Effects of liquid environments on zirconia-toughened alumina - Part I Chemical stability. Journal of Materials Science 27: 28232830.

DOI: https://doi.org/10.1007/BF00540710

Ting C.H., Ramesh S., Lwin N. \& Sutharsini U. (2016). Sintering properties and low-temperature degradation behaviour of Y-TZP ceramics. Journal of Ceramic Processing Research 17(12): 1265-1269. 
Toraya H., Yoshimura M. \& Somiya S. (1984). Calibration curve for quantitative analysis of the monoclinic-tetragonal $\mathrm{ZrO}_{2}$ System by X-Ray Diffraction. Journal of American Ceramic Society 67(6): C-119-C-121. DOI: https://doi.org/10.1111/j.1151-2916.1984.tb19715.X

Ubenthiran S., Ramesh S., Tan C.Y. \& Teng W.D. (2013). Oxygen vacancy comparisons for 3Y-TZP sintered in air and argon gas atmosphere. Applied Mechanics and Materials 372: 173-176.

DOI: https://doi.org/10.4028/www.scientific.net/AMM.37 2.173

Ubenthiran S., Thanihaichelvan M. \& Singh R. (2018). Effect of air and argon sintering atmospheres on properties and hydrothermal aging resistance of Y-TZP ceramics. Journal of Materials Engineering Performance 27: 3574-3580. DOI: https://doi.org/10.1007/s11665-018-3428-1

Vignarajah J., Murugathas T. \& Ubenthiran S. (2019). Effect of sintering holding time on tetragonal phase stability of yttria stabilised zirconia ceramics. Key Engineering Materials 803: $143-147$.
DOI: https://doi.org/10.4028/www.scientific.net/KEM.803. 143

Yasuda K., Arai S., Itoh M. \& Wada K. (1999). Influence of $\mathrm{Y}_{2} \mathrm{O}_{3}$ distribution on the rate of tetragonal to monoclinic phase transformation of yttria-stabilised zirconia during hydrothermal aging. Journal of Materials Science 34: 3597-3604.

DOI: https://doi.org/10.1023/A:1004630800871

Yoshimura M., Noma T., Kawabata K. \& Sōmiya S. (1989). Role of $\mathrm{H}_{2} \mathrm{O}$ on the degradation process of Y-TZP. In: Hydrothermal Reactions for Materials Science and Engineering (ed. S. Somiya), pp. 396-398, Springer, Dordrecht, Germany.

DOI: https://doi.org/10.1007/978-94-009-0743-0 67

Zhang F., Chevalier J., Olagnon C., Meerbeek B.V. \& Vleugels J. (2017). Slow crack growth and hydrothermal aging stability of an alumina-toughened zirconia composite made from $\mathrm{La}_{2} \mathrm{O}_{3}$-doped 2Y-TZP. Journal of European Ceramic Society 37(4): 1865-1871.

DOI: https://doi.org/10.1016/j.jeurceramsoc.2016.11.003 